\title{
Caracterização físico-química e microbiológica das águas condensadas de aparelhos de ar condicionados visando potencial reutilização
}

\author{
Physico-chemical characterization and microbiological of the \\ condensed water from air conditioners aiming reusability
}

\author{
Rosana Érika Braga de \\ Sousa \\ eng.rosanabraga@gmail.com \\ Universidade de Fortaleza \\ Carlos Márcio Soares Rocha \\ cmarcio@unifor.br \\ Universidade de Fortaleza

\section{Flávia Oliveira Monteiro da Silva Abreu \\ flavia.monteiro@uece.br Universidade Estadual do Ceará}

\section{Suellen Galvão Moraes}

Suellengalvao_m@hotmail. com

Universidade de Fortaleza

\begin{abstract}
Resumo
Neste trabalho, realizou-se a captação e a caracterização de amostras de água provenientes dos aparelhos de ar condicionados dos Blocos I e J do Centro de Ciências Tecnológicas da Universidade de Fortaleza (CCT-UNIFOR) e foi proposta uma estratégia de reutilização. Os critérios de análise físico-químicos usados foram a medida do $\mathrm{pH}$ e da condutividade elétrica, e também realizou-se a determinação quantitativa de íons sódio, potássio e cloretos. Para os parâmetros qualitativos analisouse, turbidez, cor, cálcio, magnésio, nitrito, nitrato, flúor, ferro, cloro residual, coliformes totais e E.coli. Os resultados da caracterização da água condensada do ar condicionado mostraram excelente qualidade. As demais análises encontraram-se dentro dos parâmetros estabelecidos pela Portaria do Ministério da Saúde No 2914/11 e/ou Resolução CONAMA No 357/05. Devido a excelente qualidade da água, foi proposta a construção de um reservatório para reutilização dessa água o que promoveria uma economia da ordem de 27.000L de água/dia, representando R \$ 4.200,00/mês de redução de custos.
\end{abstract}

Palavras-chave: Análises físico-químicas e microbiológicas. Qualidade. Economia.

\begin{abstract}
In this work, the capture and the characterization of samples of water from the air conditioners of the blocks I and J of Technological Sciences Centre of the University of Fortaleza (CCT-UNIFOR) and a reuse strategy. The physicochemical analysis criteria used were the measure of the $\mathrm{pH}$ and electrical conductivity, and also the quantitative determination of sodium, potassium and chloride ions. For the qualitative parameters analyzed, turbidity, colour, calcium, magnesium, nitrite, nitrate, fluoride, iron, chlorine residual, total coliforms and e. coli. The results of the characterization of condensed water from air conditioning showed excellent quality. Other analyses found within the parameters established by Ordinance of the Ministry of health $\mathrm{N}^{\circ} 2914 / 11$ and/or resolution CONAMA N $357 / 05$. Due to excellent water quality, was proposed the construction of a reservoir for reuse, with the deployment of the system could generate a daily saving of approximately $27,000 \mathrm{~L}$ proving that with the collection of these waters, the University would have a monthly savings of approximately
\end{abstract} $\$ 4,200$.

Keywords: Physical-chemical and Microbiological Analysis. Quality. Economy.

\section{Introdução}

A percepção geral, ainda comum entre as populações, é de que a água doce e renovável é um recurso infinito. Porém, sabe-se que é indispensável à vida, renovável, mas relativamente escasso e, em muitas regiões do nosso planeta, pode-se observar a decrescente oferta de água em termos de quantidade e/ou qualidade, podendo citar como principais fatores à má distribuição e mudanças do regime hidrológico que ocasionam a diminuição de pluviosidade e de recarga dos aquíferos; e 
o aumento da demanda, decorrente do crescimento acelerado da população, da expansão de atividades produtivas como a agricultura e indústria, seja para produção de grãos ou crescimento da economia. O seu desperdício e o uso inadequado como a poluição e a degradação dos mananciais também podem contribuir com a diminuição ou em um futuro não muito distante, esgotar esse recurso.

Diante de tantos fatores, se faz necessário o desenvolvimento de estratégias sustentáveis para minimizar a crise da falta de água, pois as águas doces continentais constituem um bem primordial para manter os ciclos de vida, a biodiversidade dos organismos e a sobrevivência da espécie humana. Propor alternativas de reuso e conservação da água torna-se a cada dia imprescindível, como medida para minimizar as pressões sobre os recursos hídricos.

A água doce, indispensável à vida, é um recurso renovável, mas relativamente escasso em muitas regiões da Terra. O aumento da demanda (decorrente do crescimento acelerado da população humana), seu desperdício e o uso inadequado podem esgotar ou degradar esse recurso. Acredita-se que em médio prazo, mantidas as atuais formas de uso da água, a escassez pode abranger todo o planeta, gerando uma crise global (CROOK, 1993; MOTA, 2005).

A escassez de água no mundo é agravada em virtude da desigualdade social e da falta de manejo e usos sustentáveis dos recursos naturais. De acordo com os números apresentados pela ONU - Organização das Nações Unidas - fica claro que controlar o uso da água significa deter poder. (CETESB, 2014)

O uso mais imediato ou mais importante que o ser humano faz da água é sua dessedentação, isto é, a ingestão de água para satisfazer as suas necessidades fisiológicas. Além disto, a água é utilizada pelo homem no preparo de seus alimentos, na sua higienização, no saneamento de sua moradia, na sua limpeza e outras finalidades. Para tais necessidades, a Organização Mundial de Saúde (OMS) recomenda o mínimo de 80 litros de água por dia, por habitante. (ISMB, 2011)

Há um entendimento cada vez maior, na atualidade, de que a crise de água existente é mais uma questão de governança do que de escassez física. A poluição hídrica e a escassez são, em grande medida, desafios sociais e políticos. A gestão sustentável da água é uma questão de como as pessoas, como parte de uma sociedade coletiva, administram os recursos hídricos e os benefícios associados. A falta de boa governança (incluindo políticas ineficazes, fiscalização precária, instituições fracas, corrupção), a falta de infraestrutura adequada e a escassez de novos investimentos para a capacitação de recursos humanos contribuem para o alastramento de problemas de qualidade da água. (ANA, 2013).

Dotado de grande variabilidade climática, de distintos ecossistemas e de uma gama de características que se estendem desde regiões semiáridas à Amazônia, com seu farto potencial de recursos hídricos, o Brasil apresenta condições das mais diversas, tanto no que se refere à distribuição territorial da população quanto aos seus indicadores socioeconômicos. (ANA, 2014). O Brasil passou a viver nos últimos anos, os primeiros sinais do que pode vir a ser a maior crise hídrica de sua história. Com um problema grave de seca, e também de gestão dos recursos naturais, o país vem apresentando níveis baixos em seus principais reservatórios em épocas do ano em que eles geralmente costumavam estar cheios, problema esse que em anos anteriores era sentido principalmente na região Nordeste. Essa ocorrência, de certa forma, representa uma grande contradição, já que o Brasil é considerado a maior potência hídrica do planeta. (ANA, 2014).

Apesar das grandes bacias hidrográficas que cobrem $72 \%$ do território brasileiro e de todo este potencial hídrico, há escassez de água no país devido à má distribuição da densidade populacional. O crescimento da população tem ocorrido de forma expressiva e concentrada em áreas de baixa disponibilidade hídrica. Exemplo claro é a região metropolitana de São Paulo, onde há sérios problemas de abastecimento, devido à alta demanda e a baixa disponibilidade de água, em quantidade e qualidade satisfatórias e, devido também à degradação de seus mananciais. (TELLES; COSTA, 2007).

A região Norte é a que apresenta a maior parte da disponibilidade, enquanto as regiões Nordeste e Sudeste apresentam um número menor dessas reservas, seguindo uma ordem inversamente proporcional ao número de habitantes dos respectivos lugares em questão. Na Figura 01 a seguir, podemos observar a distribuição dos Recursos Hídricos (RH) no Brasil. 
Figura 01: Distribuição dos Recursos Hídricos no Brasil.

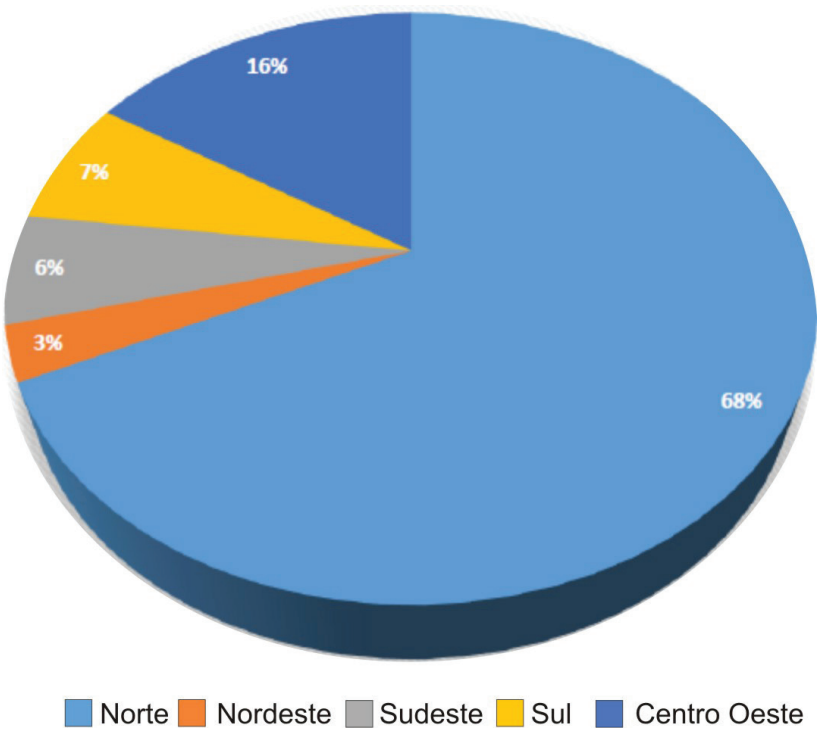

Fonte: Adaptado, ANA (2014).

A disponibilidade hídrica superficial no país é de $91.300 \mathrm{~m}^{3} . \mathrm{s}-1$ e a vazão média equivale a $180.000 \mathrm{~m}^{3} . \mathrm{s}-1$. A distribuição dos recursos hídricos superficiais, entretanto, é bastante heterogênea no território brasileiro: enquanto nas bacias junto ao Oceano Atlântico, que concentram 45,5\% da população total, estão disponíveis apenas cerca de 2,7\% dos recursos hídricos do país, na região Norte, onde vivem apenas cerca de $5 \%$ da população brasileira, estes recursos são abundantes (aproximadamente 81\%). A disponibilidade hídrica subterrânea (reserva explorável) no país corresponde a $11.430 \mathrm{~m}^{3} . \mathrm{s}-1 . ”($ ANA, 2014).

Além da má distribuição dos recursos hídricos e dos problemas de gestão no território nacional, o problema da escassez de água no Brasil também perpassa pelas recentes secas que vêm afetando o país. Nos últimos anos, principalmente em 2014 (DNOCS, 2015), os níveis de precipitação ficaram muito abaixo do esperado, por isso, os reservatórios em todo país mantiveram baixas históricas, principalmente na região Sudeste.

A escassez hídrica de algumas regiões e a adversidade das condições de suprimento de água à população urbana brasileira vem sendo objeto de estudo há anos, sem que, até o momento, tenham sido implantadas soluções globais, que permitam equacionar em definitivo os frequentes déficits de abastecimento. (ANA, 2014).

A Região Nordeste do Brasil ocupa a posição norte-oriental do país, entre $1^{\circ}$ e $18^{\circ} 30^{\prime}$ de latitude Sul e $34^{\circ} 30^{\prime}$ e $40^{\circ} 20^{\prime}$ de longitude Oeste de Greenwich. Sua área, que é de $1.219 .000 \mathrm{~km}^{2}$, equivale a aproximadamente um quinto da superfície total do Brasil, abrangendo nove Estados (Maranhão, Piauí, Ceará, Rio Grande do Norte, Paraíba, Pernambuco, Alagoas, Sergipe e Bahia) (CIRILO, 2003). Na região vivem cerca de 15,8 milhões de pessoas, dos quais 8,6 milhões estão na zona rural. (IBGE, 2010).

As grandes porções territoriais caracterizadas por clima semiárido possuem mananciais que não oferecem garantia de água para os vários tipos de usos dos recursos hídricos, em particular o abastecimento humano. Embora situada em clima tropical úmido, a zona litorânea do país também apresenta déficits hídricos, pois é composta de bacias de pequeno porte, rios com baixa vazão média e grande contingente populacional. (ANA, 2014). Essa situação pode ser explicada em razão da variabilidade temporal das precipitações e das características geológicas dominantes, onde há predominância de solos rasos baseados sobre rochas cristalinas e consequentemente baixas trocas de água entre o rio e o solo adjacente. $\mathrm{O}$ resultado é a existência de densa rede de rios temporários, tendo como maior exceção, o Rio São Francisco. Esse grande rio, porém, nasce na Serra da Canastra, em Minas Gerais, e só após centenas de quilômetros de percurso entra na região Nordeste. (CIRILO, 2007).

A gestão dos recursos hídricos tem se utilizado da implantação de reservatórios como uma importante ferramenta para o atendimento dos usos múltiplos das águas. No entanto, devido ao alto crescimento da demanda de energia elétrica 
e da água destinada ao abastecimento público, industrial e agrícola, o uso múltiplo das águas provocou o surgimento de conflitos que envolvem aspectos ambientais e operacionais, independentemente da finalidade principal do reservatório. (ANA, 2014).

Além de todas as intervenções antrópicas, as características climáticas peculiares à região do Nordeste brasileiro influenciam fortemente na disposição de água na região. No Estado do Ceará segundo a Fundação Cearense de Meteorologia e Recursos Hídricos (FUNCEME) (2012) o período chuvoso concentra-se nos meses de fevereiro, março, abril e maio. Já no o segundo semestre do ano a região passa por um período de estiagem, desta forma uma crise de água neste período pode ser resultante da falta de gerenciamento efetivo e de ações de desenvolvimentos sustentáveis mais eficazes voltadas para a resolução de problemas como a má distribuição dos recursos hídricos.

Este estudo tem como objetivo a análise físico-química e microbiológica das águas provenientes da condensação dos aparelhos de ar condicionados existentes nos Blocos I e J localizados no Centro de Ciências Tecnológicas (CCT) da UNIFOR - Universidade de Fortaleza, para que seja possível classificarmos esta água, no que se refere à sua qualidade e propor a aplicação e o teste de minimização do consumo de água potável no campus a partir da reutilização dessas águas inicialmente para atendimento de atividades menos nobres, neste caso a rega de plantas, lavagem de banheiros e limpeza de piso. Os critérios de análise escolhidos para caracterização da qualidade da água foram a determinação do $\mathrm{pH}$, condutividade elétrica, quantificar os íons sódio, potássio, cálcio e magnésio, teor de íon cloreto, turbidez, cor, nitrito, nitrato, flúor, ferro, cloro residual, coliformes totais e E.coli. Após a qualidade da água ter sido atestada, foi desenvolvido um projeto de uma cisterna para armazenamento, primeiramente em escala laboratorial, a fim de observar alterações significantes no quesito qualidade após o armazenamento e posteriormente em tamanho real, usando o programa AutoCad 2010 .

\section{Metodologia}

Foi realizado um levantamento bibliográfico através do qual se pesquisou em livros, teses, dissertações e artigos publicados sobre o tema foco desse estudo, logo em seguida direcionando-se a pesquisa para trabalhos onde os temas principais estavam relacionados a qualidade de águas para reuso. Para a etapa de coleta de água, foi realizada a identificação de todos os aparelhos existentes no campus. Dentre eles, escolheram-se oito pontos (Tabela 1) localizados nos Blocos I e J, de acordo com a acessibilidade e exposição da tubulação, onde foram realizadas as coletas das águas entre os dias 15 e 20 de julho de 2012, observando-se o tempo e volume coletado para posterior cálculo da vazão. Um segundo momento de coleta foi realizado em março de 2013 após montagem de um reservatório em escala laboratorial para teste.

Tabela 1: Pontos de coletas e especificações dos aparelhos de ar condicionado.

\begin{tabular}{c|l|c}
\hline Pontos & \multicolumn{1}{|c}{ Marca (Tipo) } & Potência (BTUs) \\
\hline A1 & Springer Carrier (split) & 48.000 \\
\hline A2 & Springer Carrier (split) & 40.000 \\
\hline A3 & Springer (split) & 36.000 \\
\hline A4 & Springer (janela) & 12.300 \\
\hline A5 & Springer (split) & 30.000 \\
\hline A6 & Springer Carrier (janela) & 21.000 \\
\hline A7 & Springer Carrier (janela) & 10.500 \\
\hline A8 & Springer (janela) & 7.500 \\
\hline
\end{tabular}

Fonte: PREFEITURA DO CAMPUS (2015)

Nota: BTUs (British Thermal Units - Unidade Térmica Britânica)

Para a coleta utilizou-se garrafas de água limpas, rotuladas com a identificação dos pontos, horário e data da coleta, devidamente fechadas e mantidas em refrigeração por 24 horas no Laboratório de Tecnologia Ambiental da Universidade de Fortaleza.

No primeiro momento de coleta realizaram-se as seguintes análises: pH, Condutividade Elétrica, Cloretos, Sódio, Potássio, Cálcio, Magnésio, Coliformes Totais e E. coli. No segundo momento, realizaram-se as mesmas análises citadas com intuito comparativo e ampliou-se os estudos com os parâmetros de Cor, Turbidez, Nitrito, Nitrato, Flúor, Ferro e Cloro Residual. Os métodos de análise seguiram referência do Standard Methods For the examination of water and wastewater (EATON, 2005). Na Tabela 02 são listados os métodos e/ou seus respectivos equipamentos utilizados. 
Tabela 02: Métodos e/ou equipamentos utilizados para análise dos parâmetros físico-químicos.

\begin{tabular}{cc} 
Parâmetros & Métodos ou Equipamentos \\
\hline Ph & Multiparâmetros - Marca: Multimer 86505 \\
\hline Condutividade Elétrica & Multiparâmetros - Marca: Multimer 86505 \\
\hline Sódio & $\begin{array}{c}\text { Espectrometria de Absorção Atômica por Chama } \\
\text { Marca: VARIAN - AA240FS }\end{array}$ \\
\hline Pótássio & $\begin{array}{c}\text { Espectrometria de Absorção Atômica por Chama } \\
\text { Marca: VARIAN - AA240FS }\end{array}$ \\
\hline Cloretos & Método Titulométrico \\
\hline Turbidez & Turbidimetro - Marca: ALFAKIT® \\
\hline Cor & $\begin{array}{c}\text { Comparação Visual com discos coloridos } \\
\text { Marca: PoliControl - NesslerQuant 200 }\end{array}$ \\
\hline Cálcio & Método Titulométrico \\
\hline Magnésio & Método Titulométrico \\
\hline Nitrito & Método da sulfanilamida - 543nm \\
\hline Nitrato & Método da sulfanilamida - 543nm \\
\hline Flúor & Colorimetria \\
\hline Ferro & Modelo: Pocket Colorimeter II - Fluoride - HACH \\
\hline Cloro Residual & Espectrometria de Absorção Atômica por Chama \\
Marca: VARIAN - AA240FS
\end{tabular}

Fonte: elaborado pelo autor.

Todas as análises foram realizadas em triplicata calculando-se o valor médio e desvio padrão para os mesmos. Foram realizadas também análises da água fornecida pela concessionária CAGECE (Companhia de Água e Esgoto do Ceará), água destilada beneficiada no próprio laboratório e água desmineralizada comercial com o intuito comparativo com a água coletada dos aparelhos.

A análise de $\mathrm{pH}$ foi realizada com um multiparâmetro de bancada da marca Multimeter 86505. Primeiro o equipamento foi calibrado com as soluções padrões de $\mathrm{pH} 4,0 ; 7,0 ; 9,0$, a seguir foi realizada a leitura das mostras. A Resolução CONAMA No 357/05 recomenda que a faixa ideal de $\mathrm{pH}$ esteja entre 6 a 9,5.

A análise de Condutividade Elétrica foi realizada em um Multiparâmetro de bancada da marca Multimeter 86505. O Fotômetro de Chama permite a determinação da presença de Sódio $(\mathrm{Na}+)$ e Potássio $(\mathrm{K}+)$. Os compostos de muitos elementos quando introduzidos na chama não luminosa de um bico de Bunsen, tornam a chama colorida; a tonalidade obtida é uma característica de cada composto.

A análise foi determinada através de Espectrometria de Absorção Atômica por Chama em um aparelho denominado fotômetro de marca e modelo: VARIAN - AA240FS. Para isso, mergulhou-se o cateter em um béquer contendo o padrão de calibração (no caso, água destilada) e ajustou-se com o controle de padrão localizado no painel do aparelho. Posteriormente, mergulhou-se o cateter em um béquer contendo as amostras coletadas e efetuou-se a leitura diretamente em um display. Cloreto, na forma de íon $\mathrm{Cl}$-, é um dos principais constituintes aniônicos presentes nas águas naturais. Para determinação de cloretos, o método utilizado foi o de Mohr, que consiste na titulação com nitrato de prata $(0,0141 \mathrm{~N}) \mathrm{em}$ $50 \mathrm{ml}$ de amostra, usando-se cromato de potássio como indicador. Com o volume gasto de nitrato de prata e multiplicandose pelo fator de correção obtivemos o valor de cloreto em mg.L-1, com o uso da (Eq. 1):

Cloreto $=(V T-V B) \times f \times 10 \mathrm{mg} . \mathrm{L}-1$

Onde:

$\mathrm{VT}=\mathrm{mL}$ de $\mathrm{AgNO} 3$ gasto na titulação da amostra;

$\mathrm{VB}=\mathrm{mL}$ de $\mathrm{AgNO} 3$ gasto na titulação do branco;

$\mathrm{f}=$ fator de nitrato de prata.

A análise de turbidez foi feita pelo Método nefelométrico com a utilização de um turbidímetro de bancada da marca ALFAKIT ${ }^{\circledR}$ de modelo Plus II. Primeiro o equipamento foi calibrado com as soluções padrões 0,$1 ; 0,8 ; 8 ; 80 ; 1000$ NTU (unidade nefelométrica de turbidez), a seguir foi realizada a leitura das amostras. 
A cor aparente é determinada usando discos coloridos de vidro especial propriamente calibrados. Esse método de comparação visual é aplicável aproximadamente a todas as amostras de água potável. Para a realização da análise, utilizou-se o comparador Visual de marca PoliControl - NesslerQuant 200 munido de disco-padrão de cor. O método utilizado consiste na titulação com a solução de EDTA $0,01 \mathrm{M}$ em $50 \mathrm{ml}$ de amostra, corrigindo o pH adicionando $1 \mathrm{ml}$ da solução tampão de hidróxido de sódio $2 \%$, utilizando aproximadamente $0,2 \mathrm{mg}$ de murexida como indicador. Com o volume gasto de EDTA e multiplicando-se pelo fator de correção obtivemos o valor da Dureza Total em CaCO3 mg.L-1, com o uso da (Eq. 2):

$m g C a . L^{-1 / L}=((V 2-V b) \times f c \times 0,01 \times 4,0 \times 1000) / V a$

Onde:

$\mathrm{V} 2=$ Volume (mL) de solução de EDTA-Na gasto na titulação da amostra;

$\mathrm{Vb}=$ Volume $(\mathrm{mL})$ de solução de EDTA-Na gasto na titulação do branco;

$\mathrm{fc}=$ fator de correção volumétrica da solução de EDTA-Na;

$\mathrm{Va}=$ Volume $(\mathrm{mL})$ da amostra.

Pela diferença de volume gasto para titular a dureza total e o cálcio obtêm-se o teor de $\mathrm{Mg}++$ com o uso da (Eq. 3):

$M g(m g . L-1)=((V 1-V 2) x f c \times 0,01 \times 2,4 \times 1000) / V a$

Onde:

$\mathrm{V} 1=$ Volume $(\mathrm{mL})$ de solução de EDTA-Na gasto na determinação da dureza total;

$\mathrm{V} 2=$ Volume $(\mathrm{mL})$ de solução de EDTA-Na gasto na determinação do cálcio;

$\mathrm{fc}=$ fator de correção volumétrica da solução de EDTA-Na;

$\mathrm{Va}=$ Volume $(\mathrm{mL})$ da amostra.

Foram medidos $10 \mathrm{ml}$ da amostra a ser analisada e colocado $10 \pm 1 \mathrm{ml}$ do padrão; adicionou-se $0,2 \mathrm{ml}$ do reagente 1 (Solução de Sulfanilamida); agitando-se e deixado em repouso por 2 minutos; depois foi adicionado 0,2 ml do reagente 2 (Solução de N-naftil- etilenodiamina); agitou-se e foi deixado em repouso por 10 minutos; sendo feita a medida da absorbância em cubetas de $10 \mathrm{~cm}$ de trajeto ótico no comprimento de onda de $543 \mathrm{~nm}$, tendo branco de reagentes como referências para calibração do equipamento. A metodologia utilizada foi o Método da sulfanilamida $-543 \mathrm{~nm}$.

O nitrogênio pode ser encontrado nas águas sob três formas distintas: Nitrogênio Orgânico, Nitrogênio Amoniacal, Nitrito e Nitrato. As duas primeiras encontram-se na forma reduzida e as duas últimas na forma oxidada. O nitrato é um composto de nitrogênio com oxigênio no estado de oxidação mais alto que pode ocorrer com o elemento de nitrogênio. Foram colocados $50 \mathrm{ml}$ da amostra em tubo de vidro graduado e adicionado $1 \mathrm{ml}$ da concentrada de amônia, e agitado; Foi feito um branco de reagentes com $50 \mathrm{ml}$ da água do mili-Q e $1 \mathrm{ml}$ da solução concentrada de amônia; Então, foi colocado aproximadamente $5 \mathrm{ml}$ da amostra na coluna até deixar verter para eliminar interferências das amostras anteriores, e colocadas na coluna, o resto da amostra; A seguir foram rejeitados os primeiros $30 \mathrm{ml}$, recolhido $10 \mathrm{ml}$ em tubo graduado; Adicionado 0,2 $\mathrm{ml}$ do reagente 1, agitado e deixado em repouso; Adicionado 0,2 $\mathrm{ml}$ do reagente 2, agitado e deixado em repouso; Após, entre 10 minutos e 2 horas, foi realizado a leitura da absorbância contra o branco de reagentes a $543 \mathrm{~nm}$. Com o resultado dado em absorbância, que serviu de base para o cálculo da concentração de nitrato (Eq.4):

$[N-N O 3] e m \mu M=C / R\{r / R .[N-N O 2]\}$

Onde:

- [N-NO2] é a concentração original de nitrito, previamente analisada em outra alíquota da amostra;

- Os valores dos rendimentos $\mathrm{R}$ e $\mathrm{r}$ são referentes à coluna na qual a amostra foi passada;

- O valor de C é específico para cada amostra analisada, que passou pela coluna redutora, sendo que:

$\mathrm{C}=$ somatório das concentrações de nitrito original dosado mais nitrato reduzido.

Em todas as análises foi feito o branco de reagente e a metodologia utilizada foi o Método da sulfanilamida $-543 \mathrm{~nm}$. 
Flúor é um elemento químico, situado no grupo dos halogênios (grupo 17) da tabela periódica dos elementos. Em sua forma biatômica (F2) e em CNTP, é um gás de coloração amarelo - pálido. É o mais eletronegativo e reativo de todos os elementos. Em sua forma ionizada (F-) é extremamente perigoso, podendo ocasionar graves queimaduras químicas se em contato com tecidos vivos. É um elemento natural encontrado em quase toda a água. A metodologia utilizada foi Colorimetria no aparelho de modelo e marca: Pocket Colorimeter II - Fluoride - HACH. O ferro presente em solução é reduzido previamente com cloridrato de hidroxilamina em meio de ácido clorídrico. Em seguida é reagido com solução de 1,10-fenantrolina em pH 3,2-3,3. Três moléculas de fenantrolina formam quelato com cada cátion de ferro II produzindo um complexo laranja avermelhado. A cor da solução obedece a Lei de lambert-Beer em $510 \mathrm{~nm}$. A intensidade da cor da solução é independente do pH no intervalo de 3 a 9. Entre pH 2,9 e 3,5 o desenvolvimento da cor é bastante rápido e a cor dos padrões são estáveis por 6 meses.

São interferentes na análise: oxidantes fortes, cianeto, nitrito, fosfatos, cromo, zinco em concentrações 10 vezes superior à concentração de ferro, cobalto e cobre em excesso de 5 mg.L-1, níquel em excesso de 2 mg.L-1. Bismuto, cádmio mercúrio, molibdato e prata são precipitados com ortofenantrolina.

Concentração mínima detectável: $10 \mu \mathrm{g} . \mathrm{L}-1$ de Ferro com cubeta de $5 \mathrm{~cm}$. Um branco deve ser realizado em paralelo com as amostras e padrões para zeragem do espectrofotômetro uma vez que os reagentes apresentam pequenas concentrações de ferro. A metodologia utilizada foi Espectrometria de Absorção Atômica por Chama no aparelho de marca e modelo: VARIAN - AA240FS.

O cloro disponível na água apresenta-se sob duas formas: HClO- ou ClO-, dependendo dos valores do pH. Com o tempo, há uma transformação destas duas formas em ácido clorídrico e consequente perda do cloro disponível. Chama-se cloro residual ao cloro que ainda não se transformou em ácido clorídrico. O resultado da análise do cloro é expresso em mg.L-1. Para a realização da análise, utilizou-se o aparelho comparador de cloro munido de discos e de cubas apropriadas no aparelho de marca e modelo PoliControl - NesslerQuant200.

Para estudo microbiológico, seguiu-se metodologia descrita por FUNASA (2009) e Colikit, sendo este último, validado frente à APHA/AWWA/WEF.

Uma alíquota de $100 \mathrm{ml}$ foi retirada da embalagem por meio de pipeta estéril e colocada em um frasco, o reagente (Colilert) foi adicionado ao frasco de água que foi agitado até a completa diluição dos grânulos. A solução foi colocada em uma cartela composta de cento e cinco cúpulas, que foi colocada em uma seladora e a solução distribuída igualmente. Em seguida, a solução foi incubada a $35^{\circ} \mathrm{C}$ em estufa por 24 horas.

A leitura foi feita com auxílio de uma lâmpada ultravioleta (115 volts, 6hz, 20 AMPS), quando da presença de coloração amarela na solução da cartela. $O$ teste era positivo para coliforme total se a cúpula mantivesse a coloração amarela e, para coliforme fecal se apresentasse coloração azul. O teste era negativo com ausência de coloração. Os resultados foram expressos de acordo com a tabela NMP (número mais provável em $100 \mathrm{ml}$ de água), onde uma cúpula positiva equivale a uma bactéria em $100 \mathrm{ml}$ de água. Os aparelhos utilizados foram a Seladora de marca QUANTITRAY ${ }^{\circledR}$ SEALER modelo 2X, Luz Ultravioleta $(365 \mathrm{~nm})$ e a Estufa Incubadora modelo Q316M2 da marca QUIMIS.

A vazão individual dos aparelhos foi determinada em regra de três simples segundo a Eq. (5):

$$
V E=(Q C * T D) / T C
$$

Onde:

$\mathrm{VE}=$ volume total estimado por hora;

$\mathrm{QC}=$ quantidade coletada;

$\mathrm{TD}=$ tempo considerado para parâmetro, que foi de uma hora;

$\mathrm{TC}=$ tempo de coleta.

Notação: considerou-se um período de $1 \mathrm{~h}$ como referencial de cálculo, devido à vazão existente de água coletada ultrapassar o volume da garrafa, se dando as mesmas coletas individuais para os pontos entre 15 e 30 minutos.

O reservatório da água foi projetado em relação ao seu dimensionamento, considerando os aspectos de espaço no terreno, o volume a ser armazenado e a localização. Para as dimensões do reservatório realizou-se os cálculos baseados em sistemas de otimização. Para projetar o esquema de localização do reservatório, assim como a sistemática da coleta, utilizou-se o programa AutoCad 2010. 
Foi realizado um levantamento, com o apoio da Prefeitura do campus, de todos os aparelhos de ar condicionados existentes na instituição e o cálculo da vazão estimado de acordo com a análise realizada nos oito pontos de coleta anteriormente.

Para caracterização da qualidade da água são determinados diversos parâmetros, os quais representam as suas características físicas, químicas e biológicas. Realizou-se neste estudo um comparativo valendo-se dos parâmetros que estabelecem os limites para a qualidade da água em potabilidade e balneabilidade de acordo com a Portaria do Ministério da Saúde N ${ }^{\circ}$ 2914/11 e Resolução CONAMA No 357/05 respectivamente. Também utilizou-se como referência os parâmetros para condutividade elétrica estabelecidos pela Farmacopeia Brasileira $5^{a}$ edição (2010). Esses parâmetros são indicadores de qualidade e comprovam a existência de impurezas quando alcançam valores superiores aos estabelecidos para determinado uso.

As amostras das águas condensadas foram caracterizadas em diversos parâmetros físico-químicos voltados para a qualidade da água, descritos a seguir.

\section{Resultados e discussão}

Diante dos resultados obtidos após todas as análises realizadas, faz-se necessário algumas observações acerca dos parâmetros encontrados tendo em vista as regulações pertinentes.

\section{Análise de pH}

A Portaria do Ministério da Saúde $\mathrm{N}^{\circ}$ 2914/11 recomenda que o pH da água seja mantido na faixa de 6,0 a 9,0 no sistema de distribuição. As restrições de faixa de pH são estabelecidas para as diversas classes de águas naturais. De acordo com a Resolução CONAMA No 357/05, para as águas doces de classe 1, pode estar entre os valores de 6,0 a 9,0. As amostras coletadas (A1-A8) tiveram o pH determinado, comparados com águas com padrão de qualidade como a amostra de água destilada (Dest.) e a água desmineralizada comercial (Desm.).Os valores encontrados estão na Figura 02.

Figura 02 - Valores de pH para água destilada (Dest.), desmineralizada comercial (Desm.), tratada fornecida pela CAGECE (Companhia de Água e Esgoto do Ceará) (AT) e as condensadas dos aparelhos de ar condicionados (A1-A8).

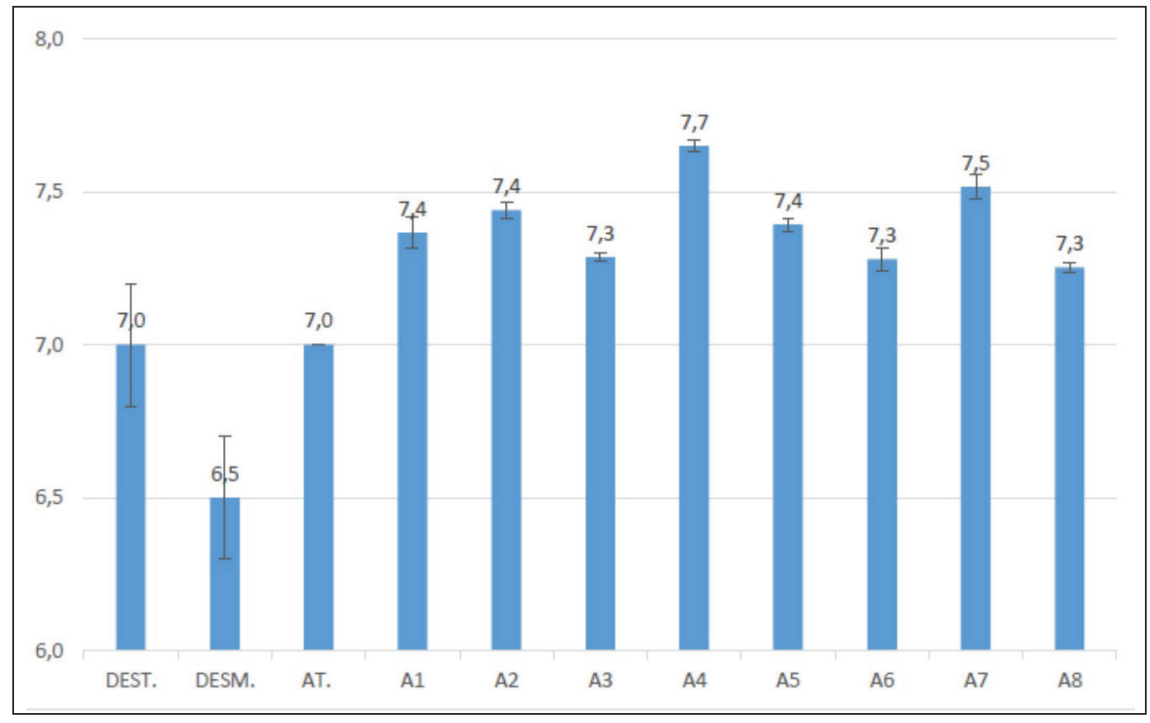

Fonte: elaborado pelo autor.

Os valores de $\mathrm{pH}$ variaram ao longo das coletas, com valores mínimos e máximos de 7,3 e 7,7 respectivamente. As águas destiladas, assim como a tratada fornecida na região, apresentaram o pH 7,0 comprovando sua neutralização e a desmineralizada comercial um valor de 6,5, considerado abaixo da média, podendo esse valor ser relacionado a data de processamento ou algum problema referente a manutenção dos aparelhos. 
Em todos as amostras analisadas, o pH enquadra-se nos padrões exigidos pelas normas citadas. Sendo o valor de $\mathrm{pH}$ um resultado importante para a composição dos "índices de qualidade de águas". De acordo com esse parâmetro, a água condensada, encontra-se apta para reuso, já que a alteração brusca ou o elevado valor do $\mathrm{pH}$ não foi observado no estudo.

\section{Análise de Condutividade Elétrica (CE) e Cloretos (Cl-)}

A condutividade elétrica está relacionada com a presença de íons dissolvidos na água, que são partículas carregadas eletricamente. Quanto maior for a quantidade de íons dissolvidos, maior será a condutividade. A condutividade depende dos seguintes fatores: presença, concentração, mobilidade e valência dos íons, bem como da temperatura.

Este parâmetro não determina especificamente quais os íons que estão presentes e somente a quantidade de íons na água, mas que poderá contribuir para reconhecimento de padrão de qualidade da água, dependendo do destino a qual lhe for dada. A Figura 03 ilustra os valores de condutividade para as amostras de ar condicionado, bem como as demais amostras comparativas.

Figura 03 - Condutividade Elétrica $(\mu \mathrm{S} / \mathrm{cm})$ e teor de Cloretos (mg.L-1) para as amostras de água destilada, desmineralizada e as oriundas dos aparelhos de ar condicionados (A1-A8). ilustra os valores de condutividade para as amostras de ar condicionado, bem como as demais amostras comparativas.

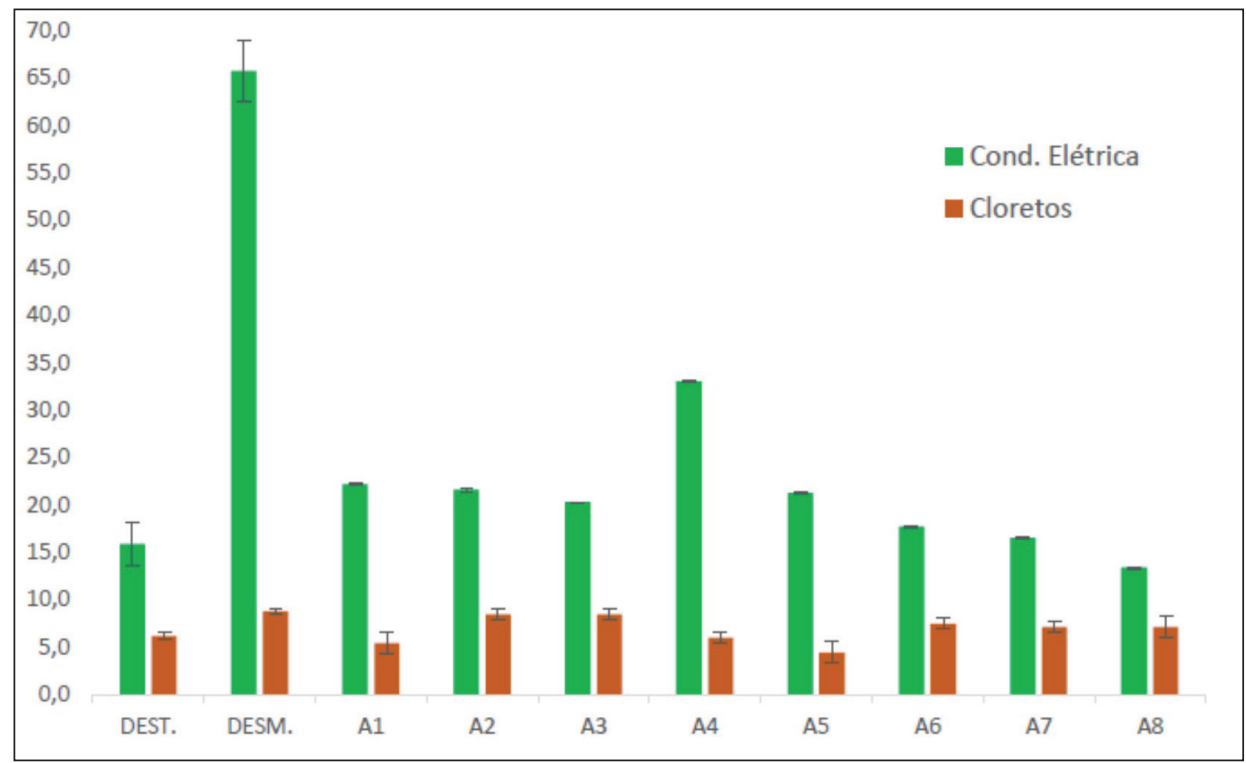

Fonte: elaborado pelo autor.

De acordo com as análises realizadas, obtiveram-se valores entre 13,28 e 32,93 $\mu \mathrm{S} . \mathrm{cm}-1$ para as amostras condensadas; A água tratada apresentou um valor de 537,2 $\mu \mathrm{S} . \mathrm{cm}-1$, ou seja, um valor mais elevado, mas ainda dentro dos padrões de potabilidade. Observa-se comparativamente que as amostras condensadas apresentaram melhor qualidade neste quesito, estando mais próximo do padrão exigido para a água Reagente, pois de acordo com a Farmacopeia Brasileira, o principal parâmetro que a caracteriza é a condutividade de 1,0 a 5,0 $\mu \mathrm{S} . \mathrm{cm}-1$. A água destilada não apresenta valores definidos pela Farmacopeia citada para esse parâmetro.

O teor de cloreto presente nas amostras foi também determinado. Os íons cloretos estão presentes em águas brutas e tratadas em concentrações que podem variar de pequenos traços até centenas de mg.L-1. Estão presentes geralmente na forma de cloretos de sódio, cálcio e magnésio. Os métodos convencionais de tratamento de água não removem cloretos. A sua remoção pode ser feita por desmineralização ou evaporação. (FUNASA, 2009)

Concentrações altas de cloretos podem restringir o uso da água para fins de potabilidade em razão do sabor que eles conferem e pelo efeito laxativo que eles podem provocar. Tanto a Portaria do Ministério da Saúde No 2914/11 que determina padrões para potabilidade quanto a Resolução CONAMA No 357/05 que trata da balneabilidade, estabelece o teor de 250 mg.L-1 como o valor máximo permitido para água. Os resultados das análises podem ser visualizados na Figura 03. 
Em geral, para as amostras condensadas (A1-A8) houve uma variação entre 4 a 8,7 mg.L-1, encontrando-se esses bem inferiores aos estabelecidos pelas normas citadas. Já para a destilada e a desmineralizada, encontramos os valores de 12,3 e 9,0 mg.L-1 respectivamente. Já a água tratada, devido a adição de cloro durante o tratamento, foi detectada valor de 134,19 mg.L-1.

Em algumas aplicações, é necessário que a água tenha um baixo teor de íons em solução, como na utilização em radiadores e maquinários, pois uma pequena concentração destes em determinados aparelhos são suficientes para causar incrustações, prejudicando o funcionamento dos mesmos. Observa-se que pelos valores de condutividade e cloretos, que as amostras (A1-A8) têm uma qualidade superior à água desmineralizada comercial, destinada a utilização em radiadores automotivos. Desta forma, pode-se avaliar posteriormente a potencialidade de utilização desta água para tal aplicação.

\section{Análise de Íons Sódio (Na+), Potássio (K+), Cálcio e Magnésio}

Os teores de íons Sódio e Potássio nas amostras de água condensada (A1-A8) foram particularmente baixos, variando entre 0,1 e 0,7 mg.L-1 para sódio e 0,1 a 0,4 mg.L-1 para potássio, muito próximos aos valores encontrados para a água destilada. Observa-se que a água desmineralizada comercial apresentou teores de sódio e potássio de 9 e 1,7 mg.L-1, respectivamente, enquanto que a água tratada apresentou valores de 35,9 e 5,2 mg.L-1. Somente o sódio é mencionado na Portaria No 2914/11 do Ministério da Saúde, tendo como valor máximo permitido 200 mg.L-1. A Resolução CONAMA 357/05 não os menciona como avaliadores de qualidade de água. Os resultados para os íons Sódio e Potássio constam na Figura 04.

Figura 04: Teor de íons Sódio $(\mathrm{Na}+)$ e Potássio $\left(\mathrm{K}_{+}\right)$contidos nas amostras de água destilada (Dest.), desmineralizada (Desm.) e as águas oriundas dos aparelhos de ar condicionado (A1-A8).

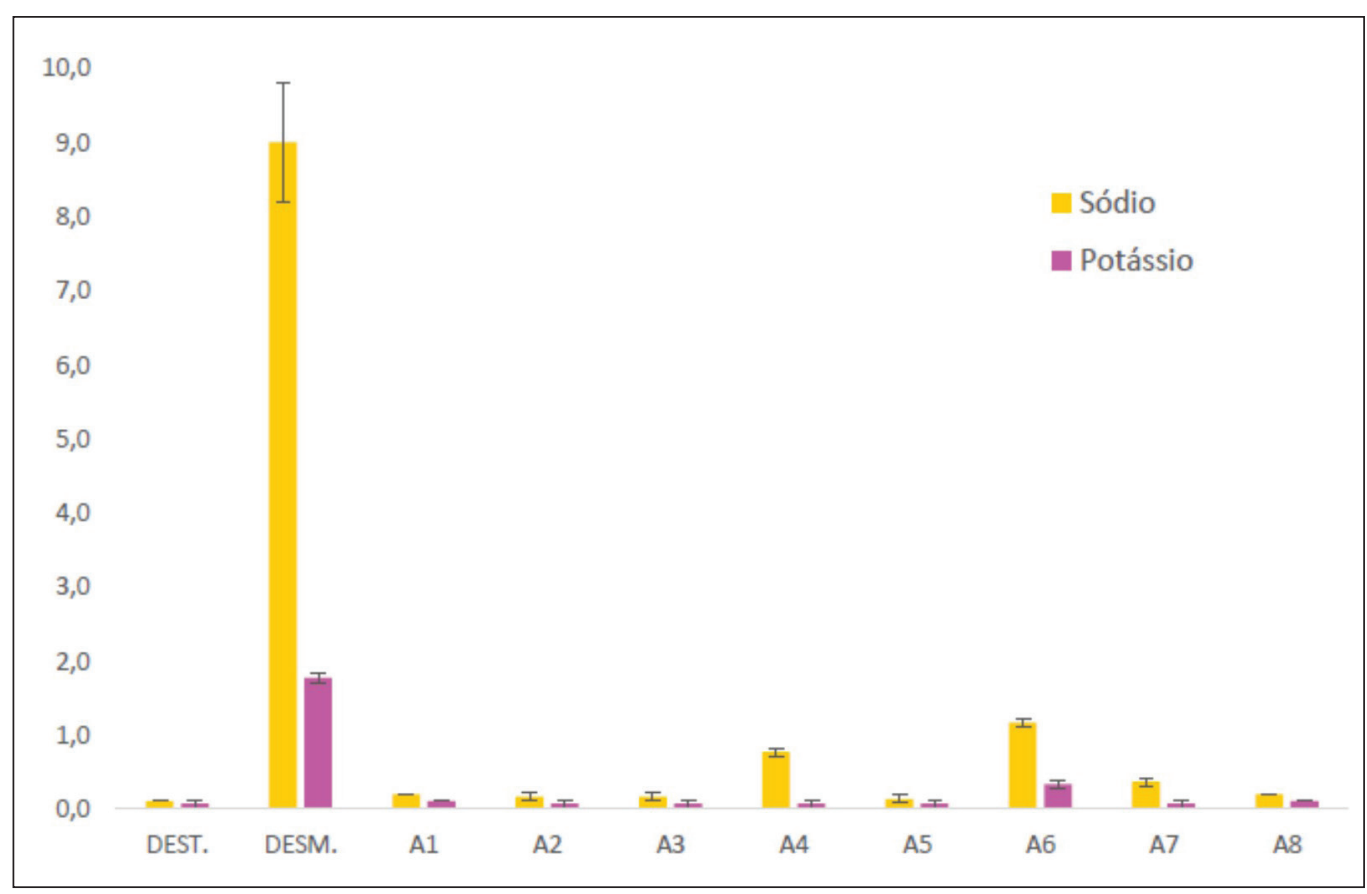

Fonte: elaborado pelo autor.

As amostras das águas condensadas encontram-se em um padrão mais próximo da qualidade de uma água destilada, com parâmetros físico-químicos melhores do que a água desmineralizada comercial e a água tratada, comprovando que a água condensada poderá ter fins de reutilização mais nobres do que irrigação e ou limpeza de ambientes, que são as estratégias comuns de reaproveitamento, pois segundo Mota (2011) as águas residuais podem ser utilizadas sem que exija uma elevada qualidade, para fins diversos, como regar plantas, lavagem de áreas externas, alimentação de bacias sanitárias, lavagem de veículos, entre outros. 
Pôde-se perceber que, dentre os íons analisados, o sódio e potássio pouco contribuem para a condutividade das amostras, pois se apresentam em menor concentração (valores inferiores a $0,7 \mathrm{mg}$.L-1) do que os íons cloreto (valores entre 4,0 e 8,7 mg.L-1), podendo-se estabelecer uma correlação entre os valores de condutividade elétrica aos teores de cloreto. Na Figura 03, observa-se que as amostras A1, A2, A3 e A5 apresentaram condutividade elétrica e teor de cloretos próximos entre si com valores médios de 21,3 $\mu$ S.cm-1 e 6,77 mg.L-1 respectivamente. As amostras A6, A7 e A8 também apresentaram semelhança, com valores médios de 15,78 $\mu \mathrm{S} . \mathrm{cm}-1$ para condutividade elétrica e $6,13 \mathrm{mg}$.L-1 para teor de cloretos. Já a amostra A4 mostrou um perfil diferenciado, pois apresentou valor de condutividade maior que as demais, sem haver a direta correspondência com os teores de cloreto, sódio ou potássio (Figuras 3 e 4). Isto é um indicativo da presença de outros íons que podem causar o aumento da condutividade. Baseado nessa observação realizou-se análise dos íons Cálcio e Magnésio nas amostras A2, A4 e A5 com seus resultados apresentados na Tabela 03 a seguir.

Tabela 03: Valores para Íons Cálcio e Magnésio encontrados nas amostras coletadas nos pontos A2, A4 e A5.

\begin{tabular}{cccc} 
İONS $\left(\mathbf{m g} \cdot \mathbf{L}^{-1}\right)$ & A2 & A4 & A5 \\
\hline Cálcio & 0,1890 & 0,6590 & 0,0660 \\
\hline Magnésio & 0,0118 & 0,1660 & $<\lim$. De detecção \\
\hline
\end{tabular}

Fonte: elaborado pelo autor.

Nos resultados para Cálcio e Magnésio, encontramos os valores de 0,6590 mg.L-1 e 0,1660 mg.L-1 respectivamente, para o ponto A4, valores elevados em relação as demais amostras, podendo-se concluir que o valor de condutividade da amostra está associado a esses íons.

A Tabela 04 resume os valores máximos e mínimos dos parâmetros analisados para as amostras de água condensada assim como os limites máximos permitidos pelos órgãos reguladores.

Tabela 04: Resumo dos parâmetros comparativos dos dados analisados da água objeto de estudo (A1-A8) com a Portaria No 2914/11 e com a Resolução CONAMA N³57/05.

\begin{tabular}{ccccc}
$\begin{array}{c}\text { Parâmetro } \\
\text { Analisado }\end{array}$ & $\begin{array}{c}\text { Valor Mínimo } \\
\text { Encontrado }\end{array}$ & $\begin{array}{c}\text { Valor Máximo } \\
\text { Encontrado }\end{array}$ & $\begin{array}{c}\text { Port. MS } \\
\mathbf{N}^{0} 2914 / 11\end{array}$ & $\begin{array}{c}\text { Res. CONAMA } \\
\mathrm{N}^{0} 357 / 05\end{array}$ \\
\hline $\mathrm{pH}$ & 7,3 & 7,7 & 6,0 a 9,0 & 6,0 a 9,0 \\
\hline $\begin{array}{c}\text { Cond. } \\
\text { Elétrica }\end{array}$ & 13,28 & 32,93 & - & - \\
\hline Cloretos & 4,8 & 8,7 & $250 \mathrm{mg} \cdot \mathrm{L}^{-1}$ & $250 \mathrm{mg} \cdot \mathrm{L}^{-1} \mathrm{CL}$ \\
\hline Sódio & 0,13 & 0,70 & $200 \mathrm{mg} \cdot \mathrm{L}^{-1}$ & - \\
\hline Potássio & 0,07 & 0,33 & - & - \\
\hline Cálcio & 0,066 & 0,659 & - & - \\
\hline Magnésio & $\begin{array}{c}<\lim . \text { de } \\
\text { detecção }\end{array}$ & 0,1660 & - & - \\
\hline
\end{tabular}

Fonte: elaborado pelo autor.

\section{Análise Microbiológica}

A água potável não deve conter microorganismos patogênicos e deve ser livre de bactérias indicadoras de contaminação fecal. Os indicadores de contaminação fecal, tradicionalmente aceitos, pertencem a um grupo de bactérias denominadas coliformes. O principal representante desse grupo de bactérias chama-se Escherichia coli. (FUNASA, 2009).

A Portaria do Ministério da saúde № 2914/11 estabelece que sejam determinados, na água, para aferição de sua potabilidade, a presença de coliformes totais e termotolerantes de preferência Escherichia Coli e a contagem de bactérias heterotróficas.

Das análises realizadas nas amostras de ar condicionado somente uma apresentou contaminantes, com valor de 119,8 NMP para Coliformes Totais e 108,6 NMP para E. coli.. No entanto, ao investigar a origem da fonte de contaminação, observou-se que o ponto de coleta era em um aparelho de ar condicionado do tipo janeleiro, e este continha uma parte do 
duto de água exposto ao ar e ao ambiente, o que causou um foco de contaminação externa. Nas demais amostras não se detectaram contaminantes.

Em suma, pode-se dizer que as amostras, quando coletadas de forma direta, evitando o contato com agentes externos contaminantes, não apresentam nenhum tipo de contaminação microbiológica.

Vazão dos aparelhos existentes nos blocos I e J

Para o cálculo da vazão por aparelho, os valores observados no momento da coleta, foram devidamente substituídos na Equação 05, com seus resultados podendo ser observados na Tabela 05.

Tabela 05: Resultados encontrados para vazão por ponto de coleta.

\begin{tabular}{c|c}
\hline Pontos & Vazão $\left(\right.$ L.. ${ }^{-1}$ ) \\
\hline A1 & 2,600 \\
\hline A2 & 4,050 \\
\hline A3 & 4,370 \\
\hline A4 & 0,475 \\
\hline A5 & 3,600 \\
\hline A6 & 1,817 \\
\hline A7 & 1,905 \\
\hline A8 & 1,227 \\
\hline
\end{tabular}

Fonte: elaborado pelo autor.

A escolha da potência do aparelho está associada diretamente com a área a ser refrigerada. No entanto, a vazão de água condensada não demonstrou proporcionalidade somente à potência do mesmo, estando também relacionado com o teor de umidade existente, o tamanho da área edificada e a movimentação de entrada e saída de pessoas no ambiente, podendo gerar maior elevação da temperatura no espaço refrigerado, e assim aumentando a carga de trabalho pelo aparelho.

Observou-se em um aparelho de 48.000 BTUs uma vazão média correspondente de 2,6 L.h-1, devido a pouca movimentação da sala e condições de refrigeração mais amenas. Já em outros pontos, como salas de grande circulação, um aparelho de 36.000 BTUs gerou uma vazão próxima de 4,4 L.h-1. No entanto, observa- se que os aparelhos tipo Split tiveram maior vazão do que qualquer aparelho do tipo janeleiro.

Para a realização do cálculo da vazão final/hora calculou-se a média entre as quatro vazões encontradas para cada tipo de aparelho, determinando-se a vazão de 1.356 1.h-1 para aparelhos do tipo janeleiro e 3.655 1.h-1 para Split.

Para a determinação da vazão total para os blocos I e J, considerou-se que alguns aparelhos como nas salas individuais de professores permanecem menos tempo ligados devido ao curto intervalo entre os horários das aulas, assim como a utilização de salas específicas, como os laboratórios, ficando esses aparelhos abaixo da média de funcionamento diária dos demais, estimada em 9 h/dia. Considerando essa diminuição de uso, considerou-se uma redução em $20 \%$ na vazão determinada.

Nos Bloco I e J existem 63 aparelhos do tipo janeleiros e 38 aparelhos do tipo Split e pode-se chegar ao valor médio de acúmulo diário de água no reservatório, considerando as vazões máxima e mínima (reduzido em 20\%), após estimativa de uso de nove horas/dia, em um volume aproximado $(\mathrm{A}+\mathrm{B})$ de $1.800 \mathrm{~L}$.

\section{Projeto do reservatório em tamanho real, ligações e planta de locação}

O reservatório de água apresentado foi projetado para atender os Blocos I e J do Centro de Ciências Tecnológicas (CCT). Com relação ao seu dimensionamento, foram considerados os aspectos de espaço no terreno, o volume a ser armazenado de acordo com a vazão e a localização. De acordo com cálculos realizados para determinação da vazão diária, pode-se estimar a vazão mensal em torno de 40.000 L.mês-1 e devido à retirada diária da água para reutilização, não gerando assim grandes acúmulos, estabeleceu-se o volume do reservatório em $6.000 \mathrm{~L}$.

No primeiro andar dos blocos, com o intuito de evitar gotejamento em contato direto com a estrutura do prédio para não danificá-la, existem tubulações conectadas aos aparelhos direcionando as águas condensadas para descarte próximo ao solo como mostra a Figura 05. 
Figura 05: Tubulação conectada ao aparelho direcionada ao solo.

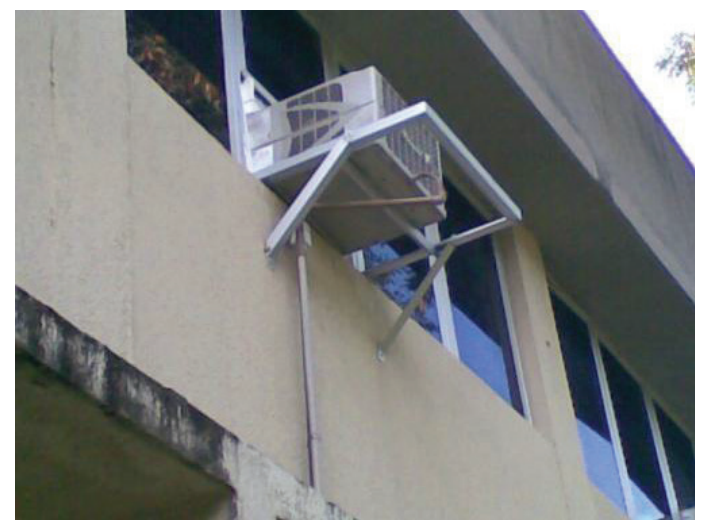

Fonte: arquivo pessoal.

Propõe-se o aproveitamento dessa tubulação existente, realizando-se uma pequena adaptação desses canos na tubulação que será interligada ao reservatório, devendo a mesma ser enterrada para evitar possíveis danos de quebra e manutenção, com declividade a ser calculada posteriormente. A planta de locação do sistema pode ser observada na Figura 06.

Figura 06: Localização da implantação do reservatório entre os blocos e direcionamento da tubulação.

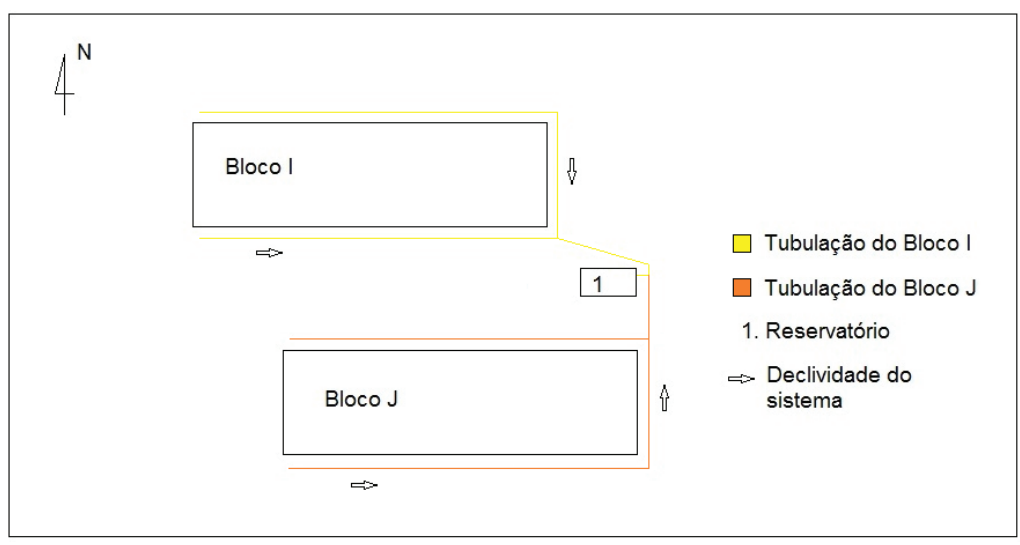

Fonte: elaborado pelo autor.

A construção do reservatório é provavelmente o item de maior peso no custo da implantação do sistema, merecendo, portanto, especial atenção. O dimensionamento do reservatório é condicionado basicamente por dois grupos de fatores: os referentes à disponibilidade de água e os relativos ao consumo. Lembra-se que o mesmo deverá conter interligado um mini reservatório (reservatório inicial) para receber primeiramente as águas permitindo a decantação de possíveis partículas visualizadas no reservatório experimental e em seguida, passando por uma tubulação elevada para o segundo tanque sendo esse o reservatório final. A Figura 07 a seguir, mostra o detalhamento do reservatório em corte e planta baixa com a localização da entrada da tubulação. 
Figura 07 - Corte e Planta Baixa do reservatório.

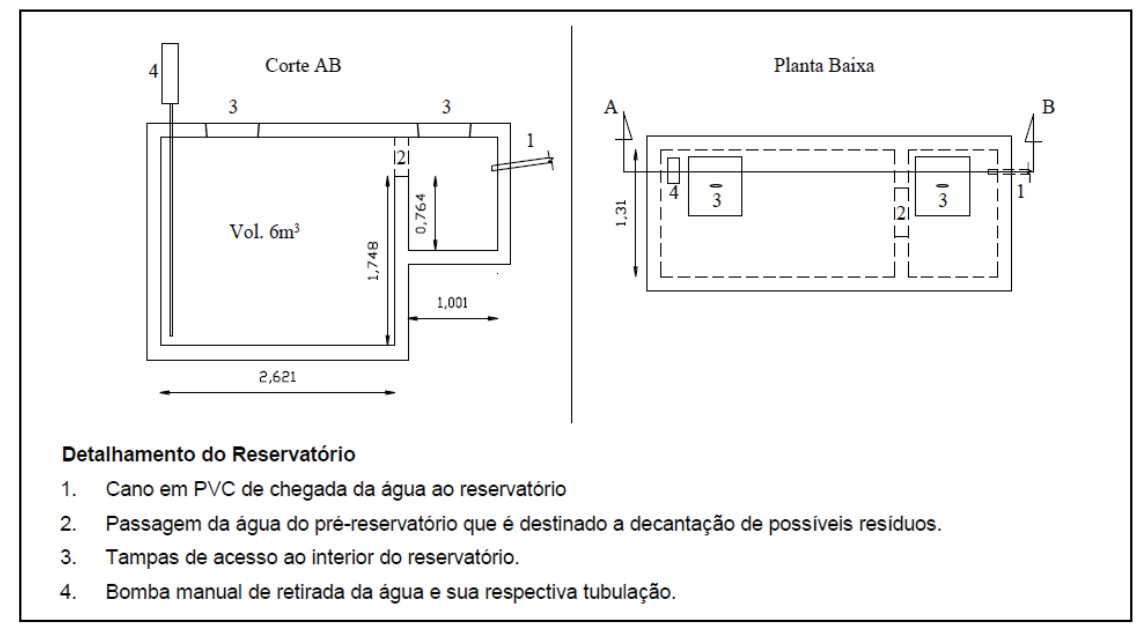

Fonte: elaborado pelo autor.

A retirada da água do reservatório seria através de uma bomba manual comum (ver detalhamento na Figura 08) até o posterior aperfeiçoamento do sistema.

Os sistemas de coleta e aproveitamento de águas condensadas requerem cuidados gerais e características construtivas que permitam a segurança da utilização, a manutenção da qualidade da água armazenada e níveis operacionais adequados. Entre estes podem ser ressaltados:

- Evitar a entrada de luz do sol no reservatório para diminuir a proliferação de algas e microrganismos;

- Manter a tampa de inspeção fechada;

- Colocar grade ou tela na extremidade de saída do dreno, para evitar a entrada de pequenos animais;

- Realizar a limpeza semestral do reservatório, removendo os possíveis sedimentos decantados;

- Projetar o reservatório de armazenamento com declividade no fundo na direção da tubulação de drenagem, para facilitar a limpeza e retirada de sedimentos;

- Assegurar que a água coletada seja utilizada somente para fins não potáveis;

- Deverão ser colocadas placas indicativas junto às torneiras de acesso geral, com a inscrição “Água não potável”.

Após análise do reservatório e tubulação existente conectada aos aparelhos, partiu-se para o orçamento da implantação do sistema de coleta. O investimento calculado, segundo orçamento dado por profissional credenciado da área da Engenharia Civil, foi de R $\$ 2.734,97$ (dois mil setecentos e trinta e quatro reais e noventa e sete centavos). Neste valor, estão incluídas todas as despesas com material e mão de obra necessária para a execução do reservatório e implantação do sistema.

No entanto, sob o foco de sustentabilidade que é a economia de água potável, que tem tido uma demanda mundial crescente, o projeto torna-se viável já que a água é um bem em crescente escassez e toda e qualquer tentativa de preservar este recurso é considerado relevante para o satisfatório gerenciamento dos recursos hídricos e com isso, a UNIFOR daria um grande salto aos critérios relacionados à sustentabilidade.

\section{Levantamento dos condicionadores de ar existentes na universidade}

As Tabelas 06 e 07 demonstram o resumo da quantidade, separadas por tipos de aparelhos de ar condicionados distribuídos nos blocos e centros de estudos existentes no campus (dados fornecidos pela Prefeitura). 
Caracterização físico-química e microbiológica das águas condensadas de aparelhos de ar condicionados visando potencial reutilização

Tabela 06: Quantidades de aparelhos de ar condicionados existentes na UNIFOR (Universidade de Fortaleza) distribuídos por blocos.

\begin{tabular}{c|c|c|c|c|c|c|c|c|c|c|c|c|c|c|c|c|c|c|c|c|}
\hline \multicolumn{10}{c|}{} & Blocos \\
\hline Tipos & A & B & C & D & E & F & H & I & J & K & L & M & N & P & Q & R & S & T & Z & Total \\
\hline Janeleiro & - & & 32 & - & 16 & - & 29 & 8 & 55 & - & 3 & - & 42 & 32 & 14 & 22 & 32 & 1 & - & $\mathbf{2 8 6}$ \\
\hline Split & 9 & 49 & 29 & 36 & 11 & 79 & 20 & 35 & 3 & 21 & 17 & 23 & 16 & 31 & 5 & 10 & 4 & 30 & 110 & $\mathbf{5 3 8}$ \\
\hline
\end{tabular}

Fonte: PREFEITURA DO CAMPUS (2015).

Tabela 07: Quantidades de aparelhos de ar condicionados existentes na UNIFOR (Universidade de Fortaleza) distribuídos por centros acadêmicos.

\begin{tabular}{l|c|c}
\multirow{2}{*}{\multicolumn{1}{c|}{ Centros }} & \multicolumn{2}{c}{ Tipos } \\
\cline { 2 - 3 } C. A. de Odontologia & Janeleiro & Split \\
\hline CCU & 3 & - \\
\hline Escolinha & - & 15 \\
\hline Ginásio & 3 & - \\
\hline NPT & 1 & 13 \\
\hline Odontologia & 12 & 3 \\
\hline Prefeitura & - & 19 \\
\hline Reitoria & 17 & 12 \\
\hline Total & 27 & 86 \\
\hline
\end{tabular}

Fonte: PREFEITURA DO CAMPUS (2015).

Com base nos dados disponibilizados pela Prefeitura do Campus sobre as quantidades de aparelhos existentes, foi realizada uma análise do custo-benefício para a implantação do sistema na instituição.

\section{Análise do custo benefício para montagem do sistema}

Considerando um sistema de aproveitamento das águas oriundas dos condensadores de ar, como toda obra dentro de um empreendimento, é de vital importância que o estudo custo/benefício mostre a viabilidade de sua execução.

Custo de investimento refere-se ao custo da solução adotada e é diretamente proporcional à quantidade de serviços necessários à realização do empreendimento. Já os custos de operação e manutenção referem-se às despesas efetivadas e disponibilizadas para execução de reparos, limpeza, inspeções periódicas e revisões, necessários ao bom funcionamento do equipamento durante sua vida útil. Os benefícios podem ser tangíveis e intangíveis sendo que os últimos não são passíveis de uma avaliação monetária (por exemplo, os benefícios alcançados através de uma conservação ambiental adequada ao meio). (TOMAZ, 2001).

O preço da água tratada, oferecida pela concessionária CAGECE (Companhia de Água e Esgoto do Ceará), é calculado por categoria. A UNIFOR (Universidade de Fortaleza), para a concessionária, enquadra-se na categoria empresarial sendo seu custo por $\mathrm{m}^{3}$ de água utilizada aproximadamente em $\mathrm{R} \$ 7,00$ (sete reais).

Levando-se em consideração o valor a ser gasto para a construção do reservatório e o preço por $\mathrm{m}^{3}$ cobrado pela concessionária, o investimento para a implantação do sistema de coleta para atendimento nos blocos I e J seria o mesmo que consumir 390,71 $\mathrm{m}^{3}$ (390.710L) de água tratada.

Considerando-se a coleta para os blocos citados aproximada em 40.000L de água condensada durante 22 dias úteis no mês, esse investimento levaria aproximadamente 10 meses para dar retorno do capital investido, considerando-se um retorno de curto prazo.

De acordo com dados especificados nas Tabelas 06 e 07, a quantidade de aparelhos existentes entre os blocos e centros acadêmicos totaliza 349 aparelhos do tipo janeleiros e 686 do tipo Split. Levando-se em consideração o volume médio diário descartado (após 9 horas de uso contínuo por dia), ao calcular a vazão para todos os aparelhos existentes no campus, a implantação do sistema poderia gerar uma economia próxima aos $27 \mathrm{~m}^{3}(27.000 \mathrm{~L})$ de água. 
Com base nos cálculos realizados para vazão de água condensada, realizou-se uma estimativa de ganho financeiro em maior prospecção para a instituição podendo-se observar em detalhes o volume médio coletado de água juntamente com suas respectivas economias na Tabela 08 .

Tabela 08: Resumo Final Volume versus Economia.

\begin{tabular}{l|c|c|c|c}
\hline Vol. X Econ. & Dia & Semana & Mês & Ano \\
\hline Volume $\left(\mathrm{m}^{3}\right)$ & 27,0 & 148,5 & 594,0 & $7.128,0$ \\
\hline Economia $(\mathrm{R} \$)$ & 189,00 & $1.039,50$ & $4.158,00$ & $49.896,00$ \\
\hline
\end{tabular}

Fonte: elaborado pelo autor.

De acordo com a análise da viabilidade econômica, a Universidade teria uma economia anual próxima dos R\$ 50.000,00 (cinquenta mil reais) gerando ganho financeiro para a instituição com a implantação do sistema de coleta das águas condensadas que atualmente, são descartadas diretamente ao solo, em todo o campus. Para a UNIFOR (Universidade de Fortaleza), a vantagem primordial da implantação do sistema seria estar preservando um bem escasso em grande parte do planeta e, contudo, adotando práticas sustentáveis ao cotidiano.

\section{Conclusão}

De acordo com os parâmetros analisados, percebeu-se que as amostras apresentaram valores medianos de condutividade inferiores a 32,93 $\mu \mathrm{S} . \mathrm{cm}-1$, cloretos $\leq 8,7 \mathrm{mg} . \mathrm{L}-1$, sódio $\leq 0,70 \mathrm{mg}$.L-1, potássio $\leq 0,4 \mathrm{mg}$.L-1, cálcio $\leq$ $0,659 \mathrm{mg}$.L-1 e magnésio $\leq 0,1660 \mathrm{mg}$.L-1. Nota-se uma relação entre o teor de cloretos e o valor de condutividade na maioria das amostras. Todos os resultados das demais análises realizadas ficaram dentro dos padrões de potabilidade de acordo com a Portaria do Ministério da Saúde No 2914/11 e/ou balneabilidade com a Resolução CONAMA No 357/05.

Em relação às análises microbiológicas realizadas, somente em uma amostra foram detectados valores de 119,8 NMP para Coliformes Totais e 108,6 NMP para E. coli. No entanto, ao investigar a origem da fonte de contaminação, observou-se que o ponto de coleta contaminado foi em um aparelho do tipo janeleiro que continha uma parte do duto de água exposto ao ar e ao ambiente, provavelmente servindo de bebedouro para pássaros, o que causou um foco de contaminação externa. Mesmo com a identificação de contaminantes na amostra, a mesma enquadra-se na Classe II de água doce, de acordo com a Resolução CONAMA No 357/05.

De maneira geral, percebe-se o grande potencial de reutilização dessa água não somente para a sugestão inicial(lavagem de pisos ou rega de plantas), pois em todos os parâmetros analisados, a água condensada apresentou características mais próximas das águas destilada e reagente do que da água potável, e melhor qualidade que a desmineralizada comercial, podendo ser dado continuidade aos estudos para utilização mais nobre.

Em relação ao cálculo da vazão, deve-se considerar que, alguns aparelhos como nas salas individuais de professores permanecem menos tempo ligados devido ao curto intervalo entre os horários das aulas, assim também como a utilização de salas específicas, como os laboratórios, que ficam abaixo da média de funcionamento diária dos aparelhos.

Apesar de não ter sido realizado o levantamento financeiro para a implantação do sistema de coleta das águas condensadas para todo o campus, pôde-se observar através do orçamento realizado para atendimento aos blocos I e J, que o retorno do capital investido se daria em torno de 10 meses após a implantação, considerando-se um investimento de curto prazo de retorno.

Respeitando as variações de potência de cada aparelho, de acordo com levantamento dos aparelhos existentes no campus, é gerada uma vazão de água condensada significativa, na qual é possível coletar aproximadamente 27.000L de água de boa qualidade diariamente de todos os aparelhos durante um dia, levando-se em consideração nove horas de uso, gerando uma economia anual próxima dos $\mathrm{R} \$ 50.000,00$ (cinquenta mil reais). Comprovou-se que esta estratégia, se aplicada de forma generalizada em polos industriais, acadêmicos e residenciais, gera economia de recursos e a preservação de um bem que é escasso e sua falta é realidade em várias regiões no mundo.

\section{Referências}

A ÁGUA no Brasil e no Mundo. Disponível em: <http://arquivos.ana.gov.br/institucional/sge/CEDOC/Catalogo/2014/ AAguaNoBrasilENoMundo2014.pdf> Acesso em: 4 maio 2015. 
Caracterização físico-química e microbiológica das águas condensadas de aparelhos de ar condicionados visando potencial reutilização

BRASIL. Fundação Nacional de Saúde. Manual prático de análise de água. 3. ed. rev. Brasília, DF: Funasa, 2009. 144p. Agência Nacional de Águas. Conjuntura dos Recursos Hídricos no Brasil: 2013. Brasília, DF: Ana, 2013. 432 p. Agência Nacional de Águas. Conjuntura dos Recursos Hídricos no Brasil: 2014. Brasília, DF: Ana, 2014. 476 p. Agência Nacional de Vigilância Sanitária. Farmacopeia Brasileira. Brasília, DF: Anvisa, 2010. 546p., 1v. il. Conselho Nacional do Meio Ambiente. Resolução n 357. Dispõe sobre a classificação dos corpos de água e diretrizes ambientais para o seu enquadramento, bem como estabelece as condições e padrões de lançamento de efluentes, e dá outras providências, de 17 de março de 2005. Diário Oficial da União, Brasília, DF, 18 mar. 2005, p. 58-63

Lei Federal no 9.433 de 8 de janeiro de 1997. Institui a Política Nacional de Recursos Hídricos, cria o Sistema Nacional de Gerenciamento de Recursos Hídricos, regulamenta o inciso XIX do art. 21 da Constituição Federal, e altera o art. $1^{\circ}$ da Lei $n^{\circ} 8.001$, de 13 de março de 1990, que modificou a Lei no 7.990 , de 28 de dezembro de 1989. Diário Oficial da União, Brasília, DF, 9 jan. 1997. Seção 1, p. 470.

Ministério da Saúde. Portaria no 2914 de 12 de dezembro de 2011. Dispõe sobre os procedimentos de controle e de vigilância da qualidade da água para consumo humano e seu padrão de potabilidade, de 12 de dezembro de 2011. Diário Oficial da União. Brasília, DF, 14 dez. 2011. Disponível em: <http://bvsms.saude.gov.br/bvs/saudelegis/gm/2011/ prt2914_12_12_2011.html>. Acesso em: 27 maio 2015.

CASTANHÃO. Disponível em: <http://www.dnocs.gov.br/barragens/castanhao/castanhao.html>. Acesso em: 19 maio 2015.

CIRILO, J. A. et al. Soluções para o suprimento de água de comunidades rurais difusas no semiárido brasileiro. Avaliação de Barragens Subterrâneas. Revista Brasileira de Recursos Hídricos, Porto Alegre, v. 8, n. 4, p. 5-24, out./dez. 2003.

CIRILO, J. A.; et al. O uso sustentável dos recursos hídricos em regiões semiáridas. Recife: Editora Universitária UFPE, 2007. $508 \mathrm{p}$.

CLARKE, R.; KING, J. O atlas da água. São Paulo: Publifolha, 2005.

CROOK, J. Critérios de Qualidade da Água para Reuso. Tradução de Hilton Felício dos Santos. Revista DAE, São Paulo, v. 53, n.174, nov./dez. 1993.

EATON, A. D. Santard methods. 21. ed. Washington: American Public Health Association, 2005.

FUNDAÇÃO CEARENSE DE METEOROLOGIA E RECURSOS HÍDRICOS. Monitoramento dos espelhos d'água dos açudes do estado do Ceará. Fortaleza, 1988. v.1.62p.

META do DNOCS é implantar 75 mil cisternas no Nordeste. Disponível em: <http://www.dnocs.gov.br/php/ comunicacao/noticias.php?f_registro $=3552 \& f \_o p c a o=i m p r i m i r \& p \_v i e w=s h o r t \& f \_h e a d e r=1 \&>$. Acesso em: 12 maio 2015.

MOTA, T. R.; OLIVEIRA, D. M.; INADA, P. Reutilização da água dos aparelhos de ar condicionado em uma escola de ensino médio no Município de Umuarama-PR. In: ENCONTRO INTERNACIONAL DE PRODUÇ̃̃O CIENTÍFICA CESUMAR, 7., 2011, Maringá. Anais Eletrônicos...Maringá: Cesumar 2011.

O PROBLEMA da escassez de água no mundo. Disponível em: $<$ http://www.cetesb.sp.gov.br/agua/\%C3\%81guas-Superficiais/37-O-Problema-da-Escassez-de-\%C3\%81gua-no-Mundo>. Acesso em: 10 mar. 2015.

QUANTOS consumimos de água. Disponível em: <http://ismb.org.br/site/index.php/2011/04/20/i-quantoconsumimos-de-agua/>. Acesso em: 15 maio 2015.

TELLES, D. D’A.; COSTA, R. H. P. G. Reúso da água: conceitos, teorias e práticas. São Paulo: Edgard Blucher, 2007. TOMAZ, P. Aproveitamento de água de chuva para fins não potáveis em áreas urbanas. 2001, cap. 9, p. 137-221. Notas fornecidas pelo autor. 
Sobre os autores

\section{Rosana Érika Braga de Sousa}

Engenheira Ambiental e Sanitarista, formada pela Universidade de Fortaleza. Atualmente é aluna de Pós-Graduação lato sensu em Engenharia de Saneamento Básico e Ambiental, pela UNICID - Universidade Cidade de São Paulo e Mestrado Acadêmico em Ciências Físicas Aplicada com ênfase em Energias Renováveis, pela UECE - Universidade Estadual do Ceará. Tem experiência na área de engenharia ambiental e sanitária, com ênfase em análises de água, implementação e acompanhamento de Programas de Gestão Ambiental e da Qualidade e Gestão de Resíduos Sólidos.

\section{Carlos Marcio Soares Rocha}

Doutor em Geologia pela Universidade Federal do Ceará (na área de Hidrogeologia e Recursos minerais 2013), Mestre em Geologia (na área de Geoquímica Ambiental 2006), Graduado em Química Industrial 2001 pela Universidade Federal do Ceará. Tem ênfase na área de Geoquímica, Qualidade de água e Hidrogeologia. Professor do Curso de Engenharia Ambiental e Sanitária da Universidade de Fortaleza (UNIFOR).

\section{Flávia Oliveira Monteiro da Silva Abreu}

Bacharel em Química pela Universidade Federal do Rio Grande do Sul (2000) e graduação em Licenciatura em Química pela Universidade Federal do Rio Grande do Sul (UFRGS) (2005). Possui Mestrado (2004) e Doutorado (2008) em Engenharia, com área de Concentração em Ciência e Tecnologia dos Materiais pelo programa de Pós-Graduação em Engenharia de Minas, Metalúrgica e Materiais (PPGEM/UFRGS). Tem experiência na área de Ciência de Materiais e Química, com ênfase em desenvolvimento de novos materiais poliméricos, atuando principalmente nos seguintes temas: Desenvolvimento de hidrogéis poliméricos em micro e nanoescala para liberação controlada de princípios ativos, Planejamento e Análise Fatorial para otimização de sistemas, modificação química de polissacarídeos, blendas de materiais poliméricos com elastômeros e na caracterização física e química de materiais poliméricos. Atuou como Bolsista de Desenvolvimento Científico Regional (DCR) na Universidade Federal do Ceará, foi professora substituta na UFRGS (2004-2005) e na UECE (2010-2011), e foi docente e pesquisadora na área de química e ciência dos materiais na Universidade de Fortaleza (UNIFOR). Atualmente é Profa. Adjunta na área de Química Geral e Analítica ( 40h/DE) no Curso de Química na Universidade Estadual do Ceará.

\section{Suellen Galvão Moraes}

Especialista em Gestão Ambiental pela Universidade de Fortaleza (2009). Bacharel em Turismo pela Faculdade Integrada do Ceará - FIC (2006). Graduanda em Engenharia Ambiental e Sanitária e monitora da disciplina de Ecossistemas Marinhos e Ambientes Costeiros, Universidade de Fortaleza. Docente e orientadora de Estágio Supervisionado do Curso Técnico de Hospedagem na Escola Profissionalizante do Estado Marly Ferreira Martins e consultora em Gestão Ambiental. 